nicamente, as bolhas rapidamente rompem deixando úlceras dolorosas com fundo necrótico e halo eritematoso. Os pacientes podem apresentar sinal de Nikolsky positivo, isto é, após fricção mecânica pode surgir uma bolha. As lesões orais podem acometer qualquer área da mucosa. O objetivo deste trabalho e relatar um caso clínico de pênfigo vulgar com manifestação oral e cutânea.

Descrição do caso clínico: Mulher de 50 anos recorre ao serviço de urgência do Hospital de São João por queixas álgicas exuberantes devido a múltiplas úlceras orais recorrentes com 1 mês de evolução, sem melhoria após antibioticoterapia, corticoterapia e terapêutica antifúngica. Ao exame objectivo apresentava múltiplas lesões orais em placa esbranquiçadas, descamativas, com eritema e raros focos hemorrágicos e algumas lesões com aspecto ulcerativo. Sem adenomegalias palpáveis. Posteriormente, ocorreu o aparecimento de bolhas na região torácica, inguinal, axilas e couro cabeludo. Apresentava também uma mancha cutânea branca na região frontal com alteração da coloração do cabelo adjacente que diz ter aparecido na idade adulta.

Discussão e conclusões: Tendo em conta o quadro clínico, suspeitou-se de uma patologia auto-imune com afecção da mucosa oral e da pele. Assim, foi proposto à doente a realização de uma biópsia oral e um estudo analítico. A biópsia veio a revelar um Pênfigo Vulgar. Iniciando desta forma terapêutica com prednisolona $60 \mathrm{mg}$ e posteriormente azatioprina $100 \mathrm{mg}$. Por ser um pênfigo refractário à terapêutica efectuada iniciou terapêutica com Rituximab 1000 mg (2 doses, separadas em 2 semanas). Mantendo-se até ao momento estável clinicamente. http://doi.org/10.24873/j.rpemd.2018.11.287

\section{\#050 Queilite Actínica: A Propósito de um Caso Clínico}

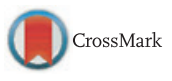

Carla Vasco*, Carolina Henriques, Orlando Lino,

Otilia Lopes, Filipe Coimbra

Faculdade de Medicina Dentária da Universidade do Porto

Introdução: A queilite actínica é uma lesão comum do lábio, induzida pela exposição crónica ou excessiva à radiação solar. Com cariz fortemente ocupacional - nomeadamente agricultores e pescadores -, atinge maioritariamente o lábio inferior, em homens caucasianos com mais de 40 anos. Normalmente de carácter crónico, pode também apresentar-se de forma aguda, esta última mais comum em jovens. A apresentação clínica pode variar entre desidratação, descamação, edema, ulceração, placas queratóticas ou erosivas/ atróficas, fissuras e perda da demarcação entre a mucosa labial e a porção cutânea do lábio. Histologicamente pode verificar-se, na mucosa, hiperplasia ou atrofia epitelial, com ou sem displasia, e hiperqueratose; e, no tecido conjuntivo, inflamação, vasodilatação e elastose solar. A queilite actínica é uma patologia potencialmente maligna, pelo que são de extrema importância o diagnóstico precoce e tratamento e seguimento adequados.

Descrição do caso clínico: Mulher, 92 anos, caucasiana. Profissão: agricultora. Sem antecedentes clínicos e/ou cirúrgicos relevantes. Apresenta-se à consulta por 'ferida no lá- bio" (sic), com evolução inferior a 6 meses, assintomática e com sangramento esporádico. Ao exame objetivo observa-se lesão ulcerada no lábio inferior à direita, na transição mucosa/epiderme, com áreas de encrustação. Mais tarde, apareceu lesão idêntica no lado oposto do lábio. Realizou-se biópsia incisional e o estudo anatomopatológico confirmou o diagnóstico de queilite actínica com displasia moderada. Foi indicada a aplicação tópica de diclofenac sódico 3\% (Solaraze ${ }^{\circledR}$ ) e creme reparador (Cicalfate ${ }^{\circledR}$ ) e cuidados de proteção solar. Ao fim de 10 semanas verificou-se remissão total das lesões no lábio.

Discussão e conclusões: Estima-se que 95\% dos carcinomas espinocelulares do lábio tenham sido precedidos por uma queilite actínica. A biópsia assume um papel importante, permitindo fazer diagnóstico diferencial, assim como perspectivar o prognóstico e o tratamento da patologia. $\mathrm{O}$ tratamento pode ser cirúrgico (vermelhonectomia) - bisturí frio, laser, criocirurgia - ou não cirúrgico - aplicação tópica de compostos como o 5-fluorouracilo ou o diclofenac, entre outros, bem como a fotoproteção e terapias fotodinâmicas. Não há, ainda, consenso relativamente à melhor estratégia terapêutica, sendo necessários mais estudos. Em qualquer circunstância, é importante o acompanhamento periódico do paciente, a fim de evitar recidivas e dimiuir o risco de malignização.

http://doi.org/10.24873/j.rpemd.2018.11.288

\section{\#051 Cimentoblastoma - apresentação de caso clínico}

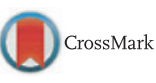

Patrícia Caixeirinho*, Marcelo Prates, Céu Machado, Ana Fernandes

Hospital de São José; Hospital de Dona Estefania

Introdução: O cimentoblastoma, descrito pela primeira vez em 1927 por Dewey, é um tumor odontogénico dos cimentoblastos, caracterizado pela proliferação de uma massa semelhante a cimento em continuidade com a raíz do dente envolvido. Trata-se de uma entidade rara e benigna, que representa menos de $1 \%$ de todos os tumores odontogênicos; $75 \%$ dos casos surgem na mandíbula e $90 \%$ nas regiões pré-molar e molar. O cimentoblastoma ocorre mais frequentemente entre a segunda e terceira décadas de vida. Os dentes decíduos raramente são afetados. Cerca de dois terços dos doentes tem dor e aumento de volume. Radiograficamente, observa-se uma massa radiopaca fundida a um ou mais dentes e circundada por um fino halo radiotransparente.

Descrição do caso clínico: Homem de 31 anos, raça negra, sem antecedentes pessoais relevantes, foi observado na consulta de Cirurgia Oral do Serviço de Estomatologia do Hospital de São José por odontalgia no dente 46 endodonciado. A dor tinha carácter espontâneo, com agravamento no último mês à mastigação. Na radiografia peri-apical observou-se lesão radiopaca de limites definidos, estendendo-se da raíz distal de 46 à raíz mesial de 47, circundada por um halo radiotransparente. A biópsia incisional foi inconclusiva. Foi feita extração de 46 e excisão da lesão; a histopatologia confirmou o diag- 